\title{
The Optimization for 2D-CD Nozzle Considering Both Aerodynamics and Geometry
}

\author{
Yaxiong Zhu ${ }^{1}$ a $^{*}$, Qiang Wang ${ }^{1}$ and Haiyang $\mathrm{Hu}^{1}$ \\ ${ }^{1}$ School of Energy and Power Engineering, Beihang University, Beijing 100191, China \\ a183671336@qq.com
}

Keywords: 2D-CD nozzle ; internal performance ; circular-to-rectangular transition duct length ; optimization.

Abstract. To master internal performance and design method of 2D-CD nozzle,the internal performance of 2D-CD nozzle was investigated by numerical simulation method.The influence of circular-to-rectangular transition duct outlet area to inlet area ratio and circular-to-rectangular transition duct length on the internal performance of 2D-CD nozzle were analyzed.The results show that a small change in internal performance happens as circular-to-rectangular transition duct outlet area to intlet area ratio decreases.Because a smaller outlet area needs a shorter convergent flap length,thus the nozzle design can be optimized in length and weight aspect.And as the circular-to-rectangular transition duct length decreases,only a little loss in internal performance is obtained.Thus the whole length and weight of nozzle can be optimized at the cost of a little loss in internal performance.

\section{Introduction}

With the development of stealth technology,much efforts has been put on the investigation of infrared stealth technology and radar stealth technology of engine. Because the 2D-CD nozzle has a great advantage over axisymmetric nozzle in infrared stealth aspect,thus the design of the 2D-CD nozzle plays an important role in the study of engine. This paper focus on a 2D-CD nozzle with a small aspect ratio in a fighter.The influence of circular-to-rectangular transition duct outlet area to inlet area ratio and circular-to-rectangular transition duct length on the internal performance of 2D-CD nozzle were analyzed by numerical simulation method.

\section{Nozzle Description}

The 2D-CD nozzle[1] mainly consists of three parts: circular-to-rectangular transition duct,convergent section and divergent section. The model is shown in Figure 1.The contour of circular-to-rectangular transition duct is designed according to superelliptic equation[2-5], as is shown in Eq.1 .In this paper,a circular-to-rectangular transition duct with a constant width(as is shown in Figure2) is studied.

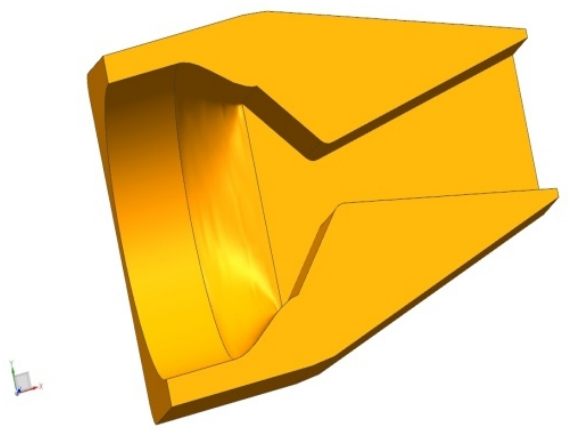

Fig. 1 The model of the 2D-CD nozzle

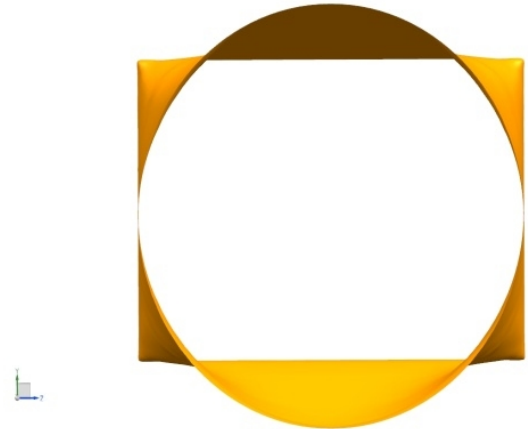

Fig. 2 The model of circular-to-rectangular transition duct 


$$
\left(\frac{Y}{a}\right)^{\gamma}+\left(\frac{Z}{b}\right)^{\gamma}=1 .
$$

\section{Numerical Approach}

The numerical simulations of this study have been carried out using Fluent of ANSYS 15.0. The equations solved are the fully three-dimensional, compressible, Reynolds averaged, Navier-Stokes equations, which are discretized in finite volume form on each of the hexahedral control volumes. Second order upwind scheme is used in the spatial discretization, and with second implicit scheme adopted for the time. The implicit density-based algorithm is used to solve the equation, and Foe-FDS is chosen for the flux type. The turbulent model is RNG $k-\varepsilon$ model,and standard wall function is adopted for wall treatment.

Because of the symmetrical characteristic,only a quarter of the entire flow field was studied.The mesh are shown in Fig. 3 and Fig.4. Fig. 3 shows the entire computational domain and Fig.4 shows the inner flow field of the nozzle. The mesh are refined near the wall.

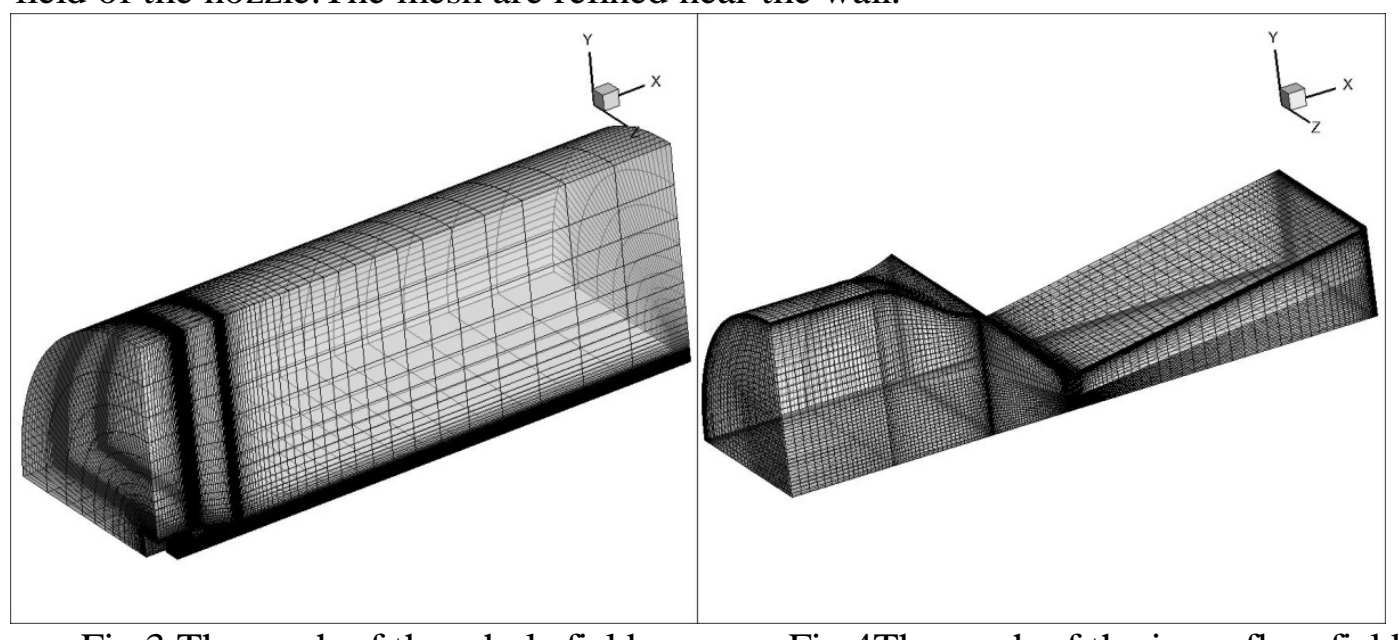

Fig. 3 The mesh of the whole field

Fig.4The mesh of the inner flow field

At the inlet of the nozzle,total temperature and total pressure are provided. At pressure-far-field boundary, static pressure, free-stream Ma and flow direction are provided. Symmetric boundary conditions are adopted at the center face. Impermeable, no-slipped and adiabatic wall boundaries are applied on the solid wall to ensure zero normal flux of mass, momentum and energy crossing the mesh face that lapped with the wall boundary.

\section{Variable Parameters Introduction}

Parameters including circular-to-rectangular transition duct outlet area to inlet area ratio and circular-to-rectangular transition duct length are investigated in this paper.For the influence of circular-to-rectangular transition duct outlet area to inlet area ratio on internal perfomance, 5 cases are discussed.Table 1 gives the detailed informations of those 5 cases. Comparing to case 1, case 2 and case 4 share the same convergent flap length,while case 3 and case 5 share the same convergent flap angle.For case 1 , the area ratio is 1 .Case 2 and case 3 have the same area ratio of 0.9 , while case 4 and case 5 share the same area ratio of 0.8 .

As for the influence of circular-to-rectangular transition duct length on internal perfomance, another 5 cases were studied.Detailed informations about these 5 cases are shown in Table 2.For a small aspect ratio nozzle in a fighter,the circular-to-rectangular transition duct length is designed 0.3 times the diameter of the inlet of circular-to-rectangular transition duct according to some surveys[6] generally. The diameter of the inlet of circular-to-rectangular transition duct studied in this paper is $1010 \mathrm{~mm}$. So the duct length of case 1 is $303 \mathrm{~mm}$.For case 6 , case 7, case 8 and case 9, the duct length is $202 \mathrm{~mm}, 252.5 \mathrm{~mm}, 353.5 \mathrm{~mm}$ and $404 \mathrm{~mm}$ respectively. 
Table 1 Cases related to the study of area ratio

\begin{tabular}{|c|c|c|c|c|c|}
\hline & Case1 & Case2 & Case3 & Case4 & Case5 \\
\hline Duct length(mm) & 303 & 303 & 303 & 303 & 303 \\
\hline Area ratio & 1 & 0.9 & 0.9 & 0.8 & 0.8 \\
\hline $\begin{array}{c}\text { Convergent flap } \\
\text { length(mm) }\end{array}$ & 415.4 & 415.4 & 359.3 & 415.4 & 300 \\
\hline
\end{tabular}

Table 2 Cases related to the study of duct length

\begin{tabular}{|l|l|l|l|l|l|}
\hline & Case1 & Case6 & Case7 & Case8 & Case9 \\
\hline Duct length(mm) & 303 & 202 & 252.5 & 353.5 & 404 \\
\hline \multicolumn{1}{|c|}{ Area ratio } & 1 & 1 & 1 & 1 & 1 \\
\hline $\begin{array}{l}\text { Convergent flap } \\
\text { length(mm) }\end{array}$ & 415.4 & 415.4 & 415.4 & 415.4 & 415.4 \\
\hline
\end{tabular}

\section{Results and Discussion}

The numerical simulations were conducted under both $11 \mathrm{~km}, 1.6 \mathrm{Ma}$ and $11 \mathrm{~km} 0.8 \mathrm{Ma}$. Fig.5 and Fig.6 shows the Mach contours and pressure contours of nozzle's internal and external flow field under $11 \mathrm{~km}, 1.6 \mathrm{Ma}$ for case 1 respectively.Fig. 7 and Fig.8 shows the Mach contours and pressure contours of nozzle's internal and external flow field under $11 \mathrm{~km}, 0.8 \mathrm{Ma}$ for case 1 respectively.

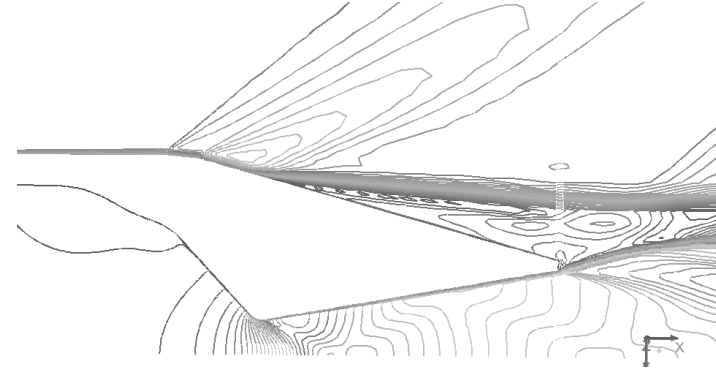

Fig.5 Mach contours of nozzle's internal and external flow field $(11 \mathrm{~km}, 1.6 \mathrm{Ma})$

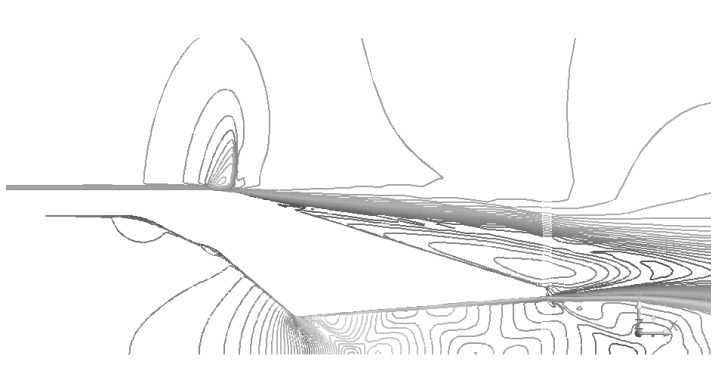

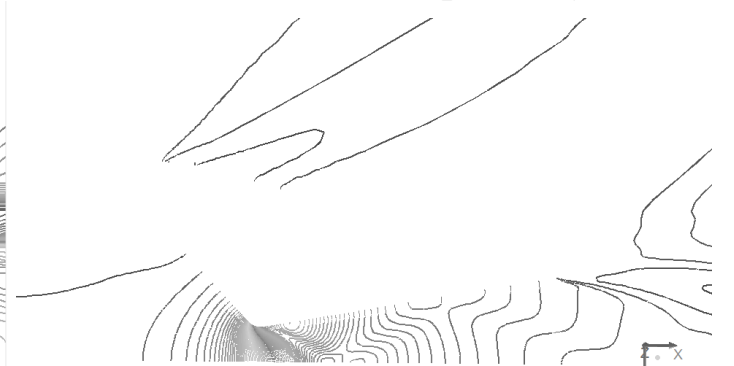

Fig.6 Pressure contours of nozzle's internal and external flow field $(11 \mathrm{~km}, 1.6 \mathrm{Ma})$

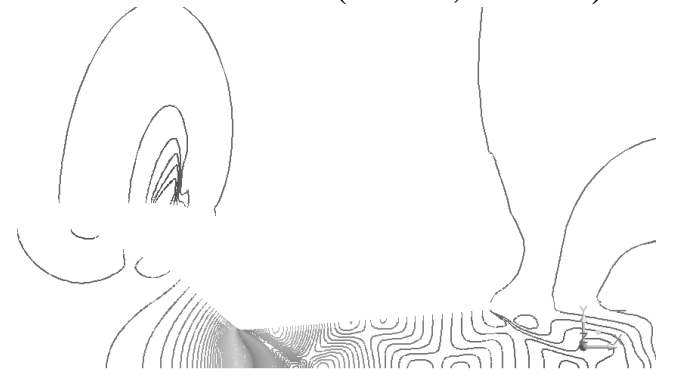

Fig.7 Mach contours of nozzle's internal Fig.8 Pressure contours of nozzle's internal and external flow field $(11 \mathrm{~km}, 0.8 \mathrm{Ma})$ and external flow field $(11 \mathrm{~km}, 0.8 \mathrm{Ma})$

The value of total pressure recovery,discharge coefficient and thrust coefficient for case 1 to case 5 are shown in Fig.9.and Fig.10. $\alpha, \mathrm{Cd}$,Cf represents total pressure recovery,discharge coefficient and thrust coefficient respectively.As we can see from these two figures, the thrust coefficient and total pressure recovery of these 5 cases changes a little.The discharge coefficient shows a trends of increase to case 1,case 2 and case4.This trend are in good agreement with the fact that the discharge coefficient is closely related to the convergent angle. Compared with case 1, minor changes happens to total pressure recovery,discharge coefficient and thrust coefficient of case 5.But considering a shorter convergent flap was provided by case 5, thus case 5 represents a better choice for nozzle design .The length of convergent flap can be reduced to $300 \mathrm{~mm}$ from $415.4 \mathrm{~mm}$ under this situation. 

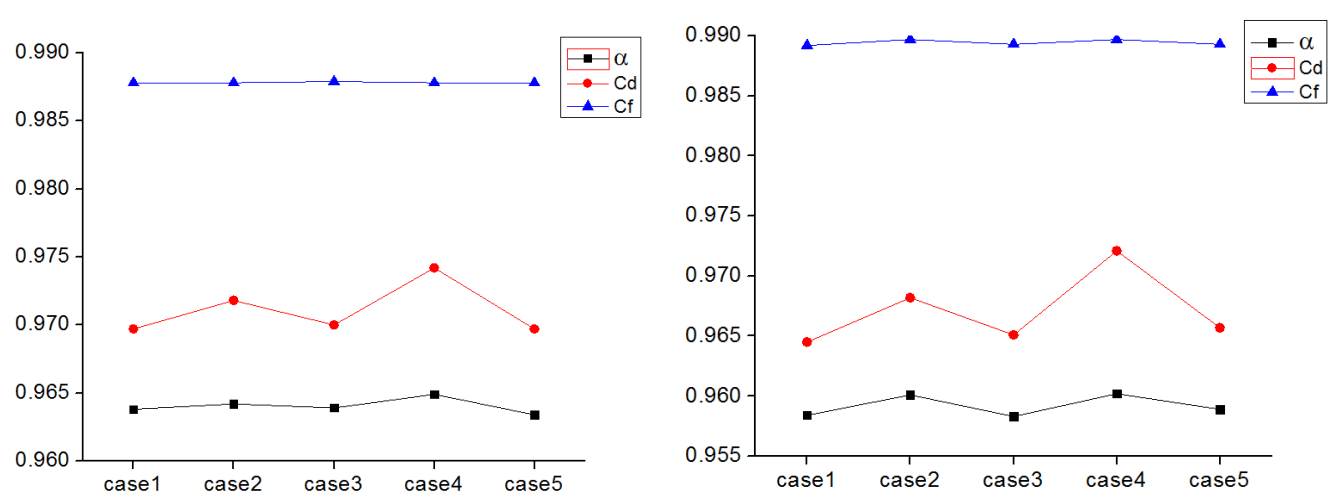

Fig.9 The internal performance of nozzle Fig.10 The internal performance of nozzle

$(11 \mathrm{~km}, 1.6 \mathrm{Ma})$

$(11 \mathrm{~km}, 0.8 \mathrm{Ma})$

The internal performance of case 6,case 7,case 1,case 8 and case 9 are shown in Fig.11 and Fig.12.From these figures, we can see the thrust coefficient of these 5 cases barely changes.But for discharge coefficient and total pressure recovery,trends of increase are shown in both two figures. This is mainly because as the circular-to-rectangular transition duct length increases, the flow separation inside the nozzle are reduced,thus a better internal performance is obtained.However,comparing to case 1,only a little loss in internal performance is found with case 6.Taking the weight and length of nozzle into considerations, case 6 provides a better nozzle design option.In this way, the circular-to-rectangular transition duct length can be shortened from $303 \mathrm{~mm}$ to $202 \mathrm{~mm}$ at the cost of a little loss in internal performance.

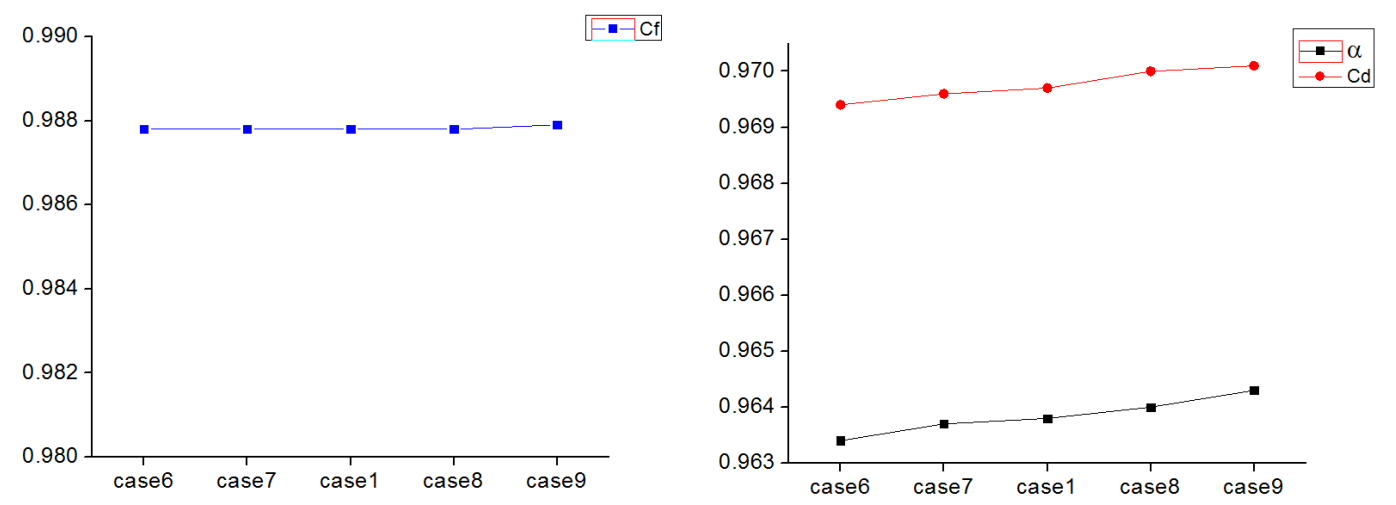

$\begin{array}{ll}\text { (a) Thrust coefficient trends } & \text { (b) discharge coefficient and total pressure recovery trends }\end{array}$

Fig.11 The internal performance of nozzle(11km,1.6Ma)

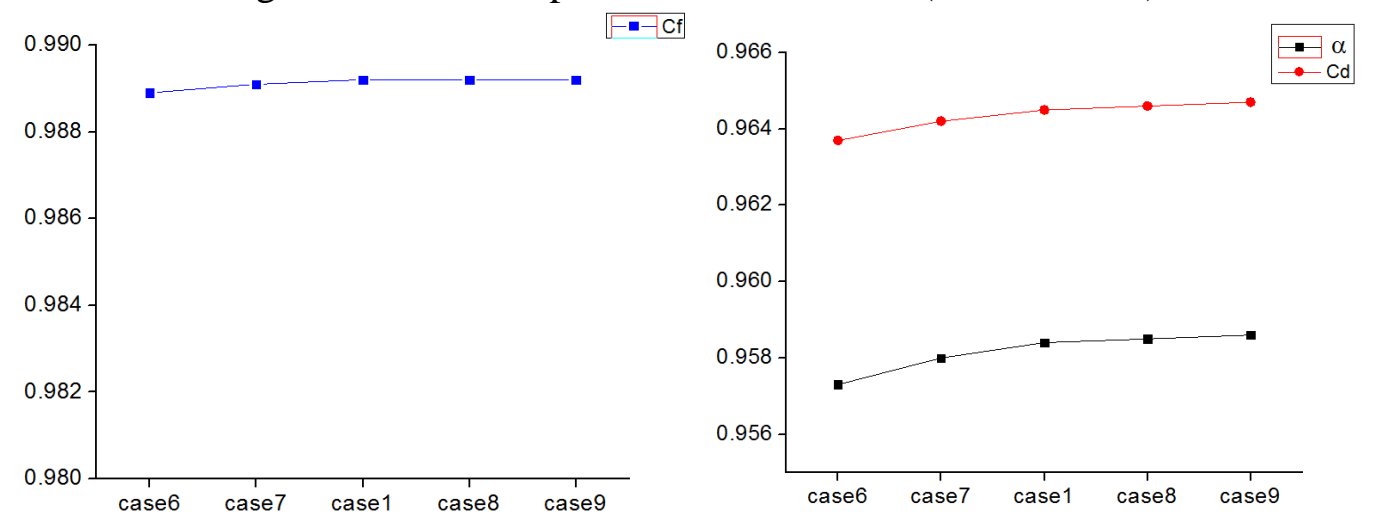

$\begin{array}{ll}\text { (a) Thrust coefficient trends } & \text { (b) discharge coefficient and total pressure recovery trends }\end{array}$

Fig. 12 The internal performance of nozzle $(11 \mathrm{~km}, 0.8 \mathrm{Ma})$ 


\section{Conclusions}

There are many factors affecting the internal performance of the 2D-CD nozzle,this paper only focused on the parameters including circular-to-rectangular transition duct outlet area to inlet area ratio and circular-to-rectangular transition duct length. When it comes to the design of 2D-CD nozzle, many other factors should be considered as well.

This paper only studied the influence of single variable on the internal performance of nozzle,further investigations should be carried out to study the influence of multivariable on the internal performance of nozzle.

The numerical simulation method can only provides a guidance to the design of nozzle,relative experiments should be carried out to gain a more accurate method for the design of nozzle.

\section{References}

[1] Heming Ji, Yubin Lei,Wanren Shao.Concept design and experimental study of the 2D-CD nozzle [J]. Aeroengine,1995,81(4):8 - 13." In Chinese"

[2] Burley II J R,Carlson J R.Circular-to-rectangular transition ducts for high-aspect-ratio nonaxisymmetric nozzles [R].AIAA-85-1346.

[3]Philip P, Doudlas T, Steven H. Heat transfer in a superelliptic transition duct [R].NASA-TP-2008-214943.

[4] Sirbaugh J R, Reichert B A. Computation of a circular-to-rectangular transition duct flow field[R]. AIAA-91-1741.

5] Reichert B A, Hingst W R , Okiishi T H.An experimental trace gas investigation of fluid transport and mixing in a circular-to-rectangular transition duct[R]. AIAA-91-2370.

[6] Xiaochun Hou,Heming Ji,Qingguo Liu, et al. Combustion technology for high performance aviation gas turbine [M].Beijing: National Defence Industrial Press , 2002:378-384. " In Chinese" 